\title{
Spectroelectrochemical studies of manganese phthalocyanine thin films for applications in electrochromic devices
}

\author{
Cheng-Lan Lin, Chia-Chi Lee, Kuo-Chuan Ho* \\ Department of Chemical Engineering, National Taiwan University, Taipei 10617, Taiwan, ROC
}

Received 5 September 2001; received in revised form 31 January 2002; accepted 31 January 2002

\begin{abstract}
The spectroelectrochemical properties of manganese phthalocyanine (MnPc) thin films are studied. Cyclic voltammetry (CV) and $\mathrm{UV}$-vis in situ spectroelectrochemistry were done to characterize the MnPc thin films. In this study, the insertion of cations during the reduction of $\mathrm{MnPc}$ thin films is proposed. Two reversible redox pairs were observed at 0 and $-0.9 \mathrm{~V}$ (vs. $\mathrm{Ag} \mid \mathrm{AgCl})$ as judged by CVs. According to the absorption spectral data, the reaction at $0 \mathrm{~V}$ is related to the transformation between $\left[\mathrm{Mn}^{\mathrm{III}} \mathrm{Pc}^{2-}\right]$ and $\left[\mathrm{Mn}^{\mathrm{II}} \mathrm{Pc}^{2-}\right]$, and the reaction at $-0.9 \mathrm{~V}$ is attributed to the transformation between $\left[\mathrm{Mn}^{\mathrm{II}} \mathrm{Pc}^{2-}\right]$ and $\left[\mathrm{Mn}^{\mathrm{I}} \mathrm{Pc}^{2-}\right]$. The polychromic characteristics of $\mathrm{MnPc}$ thin films were also observed under different redox potentials and can be expressed as follows: 0.5 (light green) $\rightarrow-0.5$ (green) $\rightarrow-0.9$ (greenish blue) $\rightarrow-1.0 \mathrm{~V}$ (purple). The electrochromism of MnPc thin films for use in electrochromic devices (ECD) is also discussed. A complementary ECD, comprising a MnPc and polyaniline (PAni) thin film couple was constructed. This device was darkened and bleached using -1.0 and $+1.0 \mathrm{~V}$, respectively. The color of the device was changed from light green to green and the transmittance of the device varied from 60 to $17 \%$ at $550 \mathrm{~nm}$. C) 2002 Elsevier Science B.V. All rights reserved.
\end{abstract}

Keywords: Manganese phthalocyanine; Polyaniline; Electrochromic; Electrochromic device

\section{Introduction}

Braun and Tscherniak first synthesized phthalocyanine (PC) in 1907 by the method given in Ref. [1]. Because of the existence of resonant conjugate double bonds in the molecular structure, PC has excellent chemical and thermal stability and also possesses semiconductor properties. When metal atoms were substituted for the two central hydrogen atoms in the PC, the new compounds were named metal phthalocyanines (MPcs). PC itself does not have electrochromic properties [2], but MPcs possess the ability to change absorbance under an applied potential. Moskalev and Kirin [3] first observed that lutetium diphthalocyanine $\left(\mathrm{Lu}(\mathrm{Pc})_{2}\right)$ thin film, which was coated on conducting

\footnotetext{
${ }_{2}$ Paper No. PT51 presented at the 9th International Conference on Electrified Interfaces, Wolfville, Nova Scotia, Canada, July 8-13, 2001.

* Corresponding author. Tel.: +886-2-2366-0739; fax: +886-22362-3040.

E-mail address: kcho@ms.cc.ntu.edu.tw (K.-C. Ho).
}

glass, had plentiful and reversible color changes. Kahl and Faulkner [4] first observed the electrochromic properties of MPcs. The electrochemical properties of MPcs, with iron, cobalt, nickel, copper and zinc as the central metals, were studied by Green and Faulkner [5]. The color changes and transmittance windows of the MPcs depend on the kind of central substituted metal. The oxidation or reduction of the central atoms causes the color changes. Thus, MPcs can be divided into two categories, oxidizing coloration and reducing coloration.

Although various electron and/or ion transfer mechanisms have been proposed for specific materials, the coloring/bleaching mechanisms of electrochromic materials in general have not yet been clearly understood. For example, the double-injection/extraction model has been widely accepted for tungsten trioxide $\left(\mathrm{WO}_{3}\right)$ [6]. That is, during the redox reactions of $\mathrm{WO}_{3}$, both electrons and cations are injected into or extracted out of the thin film to maintain its electroneutrality. Another example is Prussian blue $\left(\mathrm{Fe}_{4}\left[\mathrm{Fe}(\mathrm{CN})_{6}\right]_{3}, \mathrm{~PB}\right)$, in which the insertion or extraction of both cations and 
electrons was proposed to explain the electrochromic reaction [7]. Yet the roles of electrolytic ions during the electrochromic reactions of MPcs are not clearly understood. Most research on MPcs focused on the oxidative coloring and the assumption that anions in the electrolyte solution are inserted into the MPc thin films for charge compensation during oxidation has been proposed and widely accepted. Collins and Schiffrin [2] analyzed the $\mathrm{Lu}(\mathrm{Pc})_{2}$ thin film surface with XPS and observed that, after oxidation, anions exist on the thin film surface. However, after reduction with the same film, only a small amount of anions can be detected. Thus, the oxidation of $\mathrm{Lu}(\mathrm{Pc})_{2}$ involving the insertion of anions in the electrolytic solution was proposed. Green and Faulkner [5] analyzed the ZnPc thin film surface before and after oxidation with AES (Auger electron spectrometry) and found that anions exist everywhere within the thin film after oxidation. Kahl et al. [8] proposed that the size of the anions affects their insertion ability during the oxidation of magnesium phthalocyanine $(\mathrm{MgPc})$ thin films. Toshima et al. [9] also discussed the effect of anions $\left(\mathrm{PF}_{6}^{-}, \mathrm{ClO}_{4}^{-}, \mathrm{BF}_{4}^{-}\right.$, $\mathrm{NO}_{3}^{-}$, and $\mathrm{Cl}^{-}$) with different sizes on the oxidative reversibility of MPcs, where $\mathrm{M}$ is $\mathrm{Ni}, \mathrm{Cu}, \mathrm{Zn}, \mathrm{Co}$, and Fe.

Among many applications, the uses of MPcs in electrochromic devices have been realized during the last two decades. Because of good chemical stability and rich color changes, MPcs possess great potential in electrochromic applications. Early research focused on the rare earth metal diphthalocyanines because their redox reactions are accompanied with plentiful color changes and good reversibility [10-13]. In contrast, early work on the transition metal PCs was limited to the study of the electrochemical behavior because of the narrower choice of color change and poorer reaction reversibility. Recently, Toshima et al. $[9,14]$ studied the electrochemical properties and factors that affect the electrochromic behavior of copper phthalocyanine $(\mathrm{CuPc})$ and nickel phthalocyanine (NiPc). They discovered that the reaction reversibility could be improved by altering the operating potential or electrolytic conditions and this created a new field of use for MPcs in electrochromic applications.

In this study, a suitable operating potential window and the redox behavior of the manganese phthalocyanine $(\mathrm{MnPc})$ in aqueous based systems are investigated. During the reduction of $\mathrm{MnPc}$ thin films, the insertion of cations is proposed. The abilities of different inserted cations in the electrolytic solution were observed. However, a systematic study on the mechanistic behavior of the MnPc modified electrode is beyond the scope of the present research. No attempt was made to address the rate-limiting step for the ingress/egress processes of cations during the redox reaction of $\mathrm{MnPc}$ thin films. The possibility of using the MnPc thin film to assemble an aqueous based electrochromic device is also examined.

\section{Experimental}

All chemicals used were reagent grade. MnPc (purity $99 \%$ from Aldrich) was further purified by vacuum sublimation. By applying a temperature gradient (up to $520{ }^{\circ} \mathrm{C}$ ) to a glass tube containing un-purified $\mathrm{MnPc}$ powder under vacuum conditions, different substances will sublimate and adhere at different heights along the glass tube. Pure MnPc can thus be extracted and collected.

Transparent conducting F-doped $\mathrm{SnO}_{2}$-coated (FTO) glass was used as the electrode for all experiments. FTO glass was obtained from a local supplier (Sinonar Corporation, Hsinchu, Taiwan). Purified MnPc powders were vacuum deposited onto FTO conducting glass in a vacuum evaporation chamber. The thickness of the thin films was maintained at about $1000 \AA$ with an oscillating quartz-crystal thin film monitor (Ulvac, CRTM-5000). The deposition rate for the MnPc thin films was kept about $1 \AA \mathrm{s}^{-1}$. The total amount of $\mathrm{MnPc}$ deposited per unit electrode area was $3.8 \times 10^{-8}$ $\mathrm{mol} \mathrm{cm}{ }^{-2}$. The active dimension of the MnPc thin films was maintained at $3.0 \times 0.8 \mathrm{~cm}^{2}$ for cyclic voltammetry (CV) experiments, while the active dimension of the MnPc thin film was controlled at $2.5 \times 0.5 \mathrm{~cm}^{2}$ to make an electrochromic device. The pressure in the deposition chamber during film deposition was controlled at $2.0 \times$ $10^{-5}$ torr. The substrate was maintained at room temperature. The average sheet resistivity of the Fdoped $\mathrm{SnO}_{2}$ film was $15 \Omega \mathrm{sq}^{-1}$. The FTO glasses were washed in both $0.1 \mathrm{M} \mathrm{HCl}$ solution and then ultrasonically cleaned in deionized water for $15 \mathrm{~min}$. Deionized water was used throughout the experiments. The FTO glasses were stored in air before use. The $\mathrm{MnPc}$ thin films prepared thus were shown to be amorphous by XRD (not shown here).

The anodic electropolymerization of $\mathrm{C}_{6} \mathrm{H}_{5} \mathrm{NH}_{2}$ was used to form polyaniline (PAni) thin films. The aq. solution was composed of $1.0 \mathrm{M} \mathrm{C}_{6} \mathrm{H}_{5} \mathrm{NH}_{2}, 2.0 \mathrm{M} \mathrm{HCl}$ and deionized water. The current density and deposition time were controlled at $0.15 \mathrm{~mA} \mathrm{~cm} \mathrm{~cm}^{-2}$ and $120 \mathrm{~s}$, respectively. The as-grown PAni films formed on the FTO glass were green.

A conventional three-electrode system was used for the $\mathrm{CV}$ and potential step experiments. A Pt foil was used as a counter electrode (CE). A potassium chloride saturated silver/silver chloride electrode $(\mathrm{Ag} \mid \mathrm{AgCl})$ was used as the reference electrode (RE). All potentials were recorded and reported with respect to this RE except the operating voltage reported for the electrochromic device. An Eco Chemie (PGSTAT30) potentiostat/galvanostat was used to control the potential applied to the 
working electrode. A UV-vis spectrophotometer (Shimadzu, Model UV-1601PC) in combination with the above-mentioned potentiostat was used to collect in situ absorption spectra or absorbance changes in the $\mathrm{MnPc}$ thin films under various applied voltages.

\section{Results and discussion}

\subsection{Determination of the potential window for $M n P c$}

In an effort to determine a suitable operating potential window for the $\mathrm{MnPc}$ thin film electrode, $\mathrm{CV}$ experiments scanned over different potential ranges were first conducted. The CVs of the $\mathrm{MnPc}$ thin film in 1 $\mathrm{M} \mathrm{KCl}$ solution is shown in Fig. 1, in which the potential was scanned between -1.50 and $1.50 \mathrm{~V}$ (vs. $\mathrm{Ag} \mid \mathrm{AgCl})$ for the first three cycles. The potential was scanned from 0 to $-1.50 \mathrm{~V}$ first and the color of the thin film changed from light green to purple in this potential range. Two major reduction peaks appeared at -1.10 and $-1.25 \mathrm{~V}$ in the first cycle of the potential scan. Only the peak at $-1.10 \mathrm{~V}$ remained after the second potential scan. The peak at $-1.25 \mathrm{~V}$ decreased rapidly with an increase in the cycle number. There was only one distinctive oxidation peak occurring at $1.20 \mathrm{~V}$ when the potential was scanned between 0 and $1.50 \mathrm{~V}$, corresponding to a color change from light green to light yellow. This oxidation reaction apparently is irreversible. The oxidation peak vanished after three $\mathrm{CV}$ cycles and no color changes in the MnPc thin film were observed with a further potential scan. In order to avoid irreversible reactions at -1.25 and $1.20 \mathrm{~V}$, the potential window for $\mathrm{MnPc}$ thin film was chosen between -1.20 and $0.50 \mathrm{~V}$.

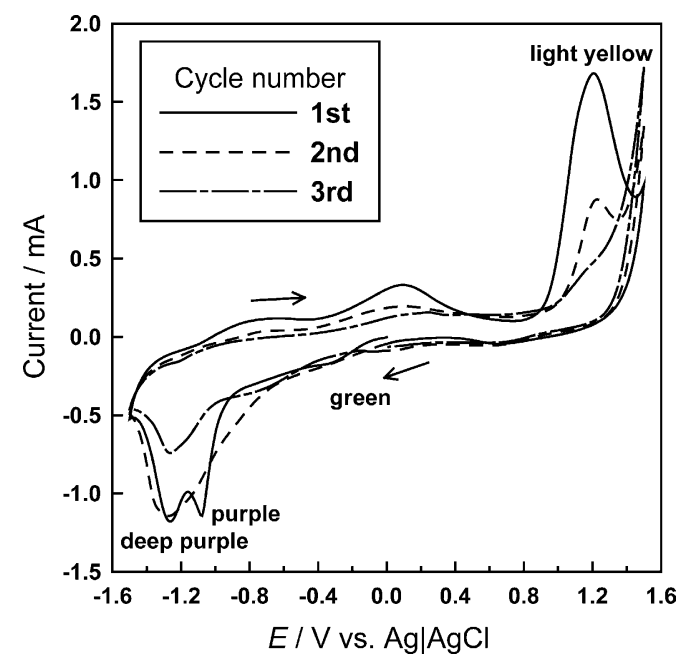

Fig. 1. Cyclic voltammograms of the MnPc thin film on a conductive FTO glass tested for three cycles in a $1 \mathrm{M} \mathrm{KCl}$; scan potential = $1.50-1.50 \mathrm{~V}$ (vs. $\mathrm{Ag} \mid \mathrm{AgCl}$ ), scan rate $=50 \mathrm{mV} \mathrm{s}^{-1}$, electrode area $=$ $2.4 \mathrm{~cm}^{2}$.

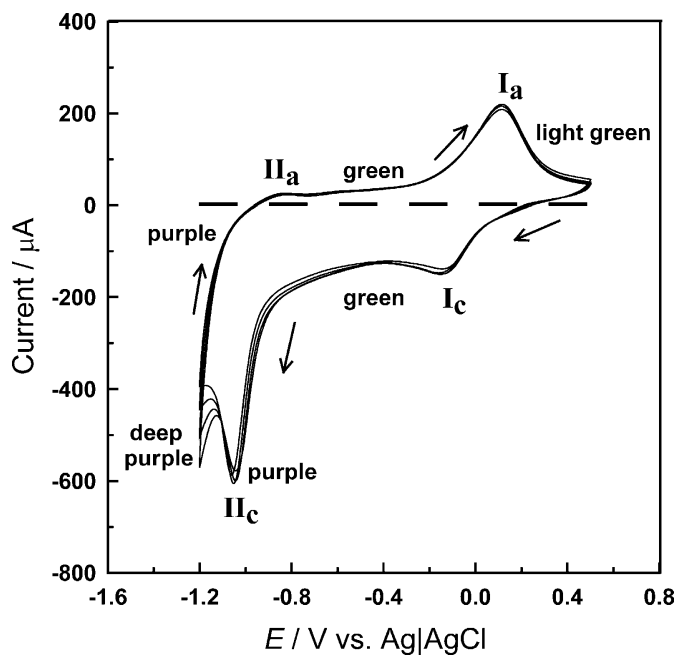

Fig. 2. Cyclic voltammograms of the MnPc thin film on a conductive FTO glass tested for three cycles in a $1 \mathrm{M} \mathrm{KCl}$; scan potential $=-$ $1.20-0.50 \mathrm{~V}$ (vs. $\mathrm{Ag} \mid \mathrm{AgCl}$ ), scan rate $=20 \mathrm{mV} \mathrm{s}^{-1}$, electrode area $=$ $2.4 \mathrm{~cm}^{2}$. The background current for the conductive FTO glass is indicated by the dashed line. See Table 1 for corresponding peak potentials.

Fig. 2 shows the CVs of the MnPc thin film in $1 \mathrm{M}$ $\mathrm{KCl}$ solution, in which the potential was scanned between -1.20 and $0.50 \mathrm{~V}$. The background current for the FTO glass, in the absence of the MnPc film, is shown by the dashed line. The reversibility of the redox behavior was greatly improved as compared to the results presented in Fig. 1. The MnPc thin film switched from light green to green and then purple as the potential was scanned from 0.5 to $-1.2 \mathrm{~V}$ (vs. $\mathrm{Ag} \mid \mathrm{AgCl})$, and vice versa. There are two oxidation peaks at $-0.85\left(\mathrm{II}_{\mathrm{a}}\right)$ and $0.11 \mathrm{~V}\left(\mathrm{I}_{\mathrm{a}}\right)$ and two reduction peaks at $-0.13\left(\mathrm{I}_{\mathrm{c}}\right)$ and $-1.03 \mathrm{~V}\left(\mathrm{II}_{\mathrm{c}}\right)$. The $\mathrm{MnPc}$ thin film changed to green when the potential was scanned negatively passing through the reduction peak $\left(\mathrm{I}_{\mathrm{c}}\right)$ around $-0.13 \mathrm{~V}$, and then reached purple when the potential passed through $-0.85 \mathrm{~V}\left(\mathrm{II}_{\mathrm{a}}\right)$. The purple color became increasingly deeper as the potential scan passed $-1.05 \mathrm{~V}\left(\mathrm{II}_{\mathrm{c}}\right)$ before reversing at $-1.20 \mathrm{~V}$. The redox potentials and their corresponding color states are summarized in Table 1.

In Fig. 2, for the reduction peak $\left(\mathrm{I}_{\mathrm{c}}\right)$ at $-0.13 \mathrm{~V}$ and the oxidation peak $\left(\mathrm{I}_{\mathrm{a}}\right)$ at $0.11 \mathrm{~V}$, the reversible color switch in the thin film corresponding to both peaks is

Table 1

The corresponding colored states of $\mathrm{MnPc}$ thin films change as a function of the redox potential

\begin{tabular}{lrl}
\hline Redox peaks & Peak potential/V & Color state \\
\hline Reduced $\mathrm{I}_{\mathrm{c}}$ & -0.13 & Green \\
Oxidized $\mathrm{I}_{\mathrm{a}}$ & 0.11 & Light green \\
Reduced $\mathrm{II}_{\mathrm{c}}$ & -1.03 & Purple \\
Oxidized $\mathrm{II}_{\mathrm{a}}$ & -0.85 & Green \\
\hline
\end{tabular}

See Fig. 2 for details. 
between light green and green, which can be considered as a pair of redox couples. Similarly, the reduction peak $\left(\mathrm{II}_{\mathrm{c}}\right)$ at $-1.03 \mathrm{~V}$ and the oxidation peak $\left(\mathrm{II}_{\mathrm{a}}\right)$ at -0.85 $\mathrm{V}$, corresponding to the color switching between green and purple, should be considered as another pair of redox couples. The thin film becomes deep purple after the potential scan passes $-1.10 \mathrm{~V}$. Since the current decays rapidly with the increasing number of scans and no corresponding oxidation peak can be observed, there should be an irreversible reduction reaction at potentials more negative than $-1.10 \mathrm{~V}$. According to the direct observation of color changes and CVs, it can be concluded that the redox reactions of $\mathrm{MnPc}$ thin film involve two reversible redox reactions in the potential range between 0.5 and $-1.10 \mathrm{~V}$. The corresponding formal potentials, $E^{0^{\prime}}$, are -0.01 and $-0.94 \mathrm{~V}$ for reactions in peaks I and II, respectively.

There are, at least, two major redox mechanisms being proposed for MPcs in non-aqueous media [1517]. The first is the redox reaction for the central metal ion. The second is the electron transfer that occurs on the PC ring. The redox reaction mechanisms and corresponding $\mathrm{MnPc}$ potentials in different organic solutions are listed in Table 2. At the potential of 0.0 $\mathrm{V}$ (vs. $\mathrm{Ag} \mid \mathrm{AgCl}$ ) where $\left[\mathrm{Mn}^{\mathrm{II}} \mathrm{Pc}^{2-}\right]$ can be easily oxidized into $\left[\mathrm{Mn}^{\mathrm{III}} \mathrm{Pc}^{2-}\right]$, this is close to the redox pair $\left(\mathrm{I}_{\mathrm{c}}\right.$ and $\left.\mathrm{I}_{\mathrm{a}}\right)$ with $E^{0^{\prime}}$ equal to $-0.01 \mathrm{~V}$ as is evident in Fig. 2. Therefore, this can be considered as the redox reaction of the central manganese ion. After the $\left[\mathrm{Mn}^{\mathrm{III}} \mathrm{Pc}^{2-}\right]$ thin film is reduced to $\left[\mathrm{Mn}^{\mathrm{II}} \mathrm{Pc}^{2-}\right]$, a further reduction can occur at the central manganese ion to form $\left[\mathrm{Mn}^{\mathrm{I}} \mathrm{Pc}^{2-}\right]$ or on the $\mathrm{PC}$ ring to form $\left[\mathrm{Mn}^{\mathrm{II}} \mathrm{Pc}^{3-}\right]$. According to Table 2, the former reduction occurs at a potential around $-0.9 \mathrm{~V}$ (vs. SCE) and the latter at a potential around $-0.75 \mathrm{~V}$ (vs. SCE). Therefore, the redox potential $\left(\mathrm{II}_{\mathrm{c}}\right.$ and $\left.\mathrm{II}_{\mathrm{a}}\right)$ at $-0.95 \mathrm{~V}$ in Fig. 2 can be assigned as the reduction of $\left[\mathrm{Mn}^{\mathrm{II}} \mathrm{Pc}^{2-}\right]$ into $\left[\mathrm{Mn}^{\mathrm{I}} \mathrm{Pc}^{2-}\right]$. When the potential scan passes $-1.1 \mathrm{~V}$ in the negative direction, manganese ions cannot undergo further reduction. The reduction therefore takes place on the PC ring. According to Table 2, the reduction of $\left[\mathrm{Mn}^{\mathrm{I}} \mathrm{Pc}^{2-}\right]$ into $\left[\mathrm{Mn}^{\mathrm{I}} \mathrm{Pc}^{3-}\right]$ occurred at $-1.18 \mathrm{~V}$ (vs. SCE), which is close to the onset potential of an irreversible reduction reaction observed around -1.10 V.

\subsection{Reduction absorbance spectra of the MnPc thin film}

The amount of electroactive MnPc per unit electrode area was obtained by integrating the CV peak after background current subtraction at a slow sweep rate and was $2.2 \times 10^{-8} \mathrm{~mol} \mathrm{~cm}^{-2}$. Since the total amount of $\mathrm{MnPc}$ deposited per unit area was known, it was estimated that about $58 \%$ of the deposited MnPc was electroactive.

The absorbance spectra of the MnPc thin films under different applied potentials are presented in Fig. 3. Negative potentials applied to the MnPc thin films decrease from 0.2 (near equilibrium potential) to $-1.4 \mathrm{~V}$ successively, with a decrement of $0.1 \mathrm{~V}$. Meanwhile the corresponding absorbance spectra are recorded when the steady-state current is reached. The reduction spectra for $\mathrm{MnPc}$ thin films showed three stages. The potentials between 0.2 and $-0.6 \mathrm{~V}$ represent stage I, where the absorbance spectra of the $\mathrm{MnPc}$ thin films are shown in Fig. 3(a). A constant absorbance spectrum is obtained between 0.2 and $-0.4 \mathrm{~V}$. At $-0.4 \mathrm{~V}$, a major absorbance peak at $690 \mathrm{~nm}$ was initially observed. When the applied potential reached $-0.6 \mathrm{~V}$, the peak at 690 $\mathrm{nm}$ became distinctive and the peak at $730 \mathrm{~nm}$ vanished. The color of the MnPc thin films did not change conspicuously. Some slight blue spots, scattered over the green thin film, were observed. Since there was no corresponding reduction peak observed in this potential region $(-0.4$ to $-0.6 \mathrm{~V})$, as seen in Fig. 2, the blue spots might be responsible for the absorption peak observed at $690 \mathrm{~nm}$. The origin of the blue spots is still unknown and deserves further study. At stage II, as shown in Fig.

Table 2

Voltammetric data for MnPc redox couples in several organic solutions

\begin{tabular}{lllrl}
\hline Solvent & Supporting electrolyte & Redox couple & $E / \mathrm{V}$ vs. SCE & Reference \\
\hline DMF & $\left(\mathrm{C}_{2} \mathrm{H}_{5}\right)_{4} \mathrm{NClO}_{4}$ & {$\left[\mathrm{Mn}^{\mathrm{II}} \mathrm{Pc}^{2-}\right] /\left[\mathrm{Mn}^{\mathrm{II}} \mathrm{Pc}^{-}\right]$} & 0.72 & {$[15]$} \\
Pyridine & $\left(\mathrm{C}_{2} \mathrm{H}_{5}\right)_{4} \mathrm{NClO}_{4}$ & {$\left[\mathrm{Mn}^{\mathrm{III}} \mathrm{Pc}^{2-}\right]\left[\mathrm{Mn}^{\mathrm{II}} \mathrm{Pc}^{2-}\right]$} & 0.01 & {$[16]$} \\
DMSO & $\left(\mathrm{C}_{2} \mathrm{H}_{5}\right)_{4} \mathrm{NClO}_{4}$ & & -0.08 & {$[17]$} \\
DMF & $\left(\mathrm{C}_{2} \mathrm{H}_{5}\right)_{4} \mathrm{NClO}_{4}$ & & -0.12 & {$[17]$} \\
DMF & $\left(\mathrm{C}_{2} \mathrm{H}_{5}\right)_{4} \mathrm{NClO}_{4}$ & {$\left[\mathrm{Mn}^{\mathrm{II}} \mathrm{Pc}^{2-}\right] /\left[\mathrm{Mn}^{\mathrm{II}} \mathrm{Pc}^{3-}\right]$} & -0.69 & {$[17]$} \\
DMSO & $\left(\mathrm{C}_{2} \mathrm{H}_{5}\right)_{4} \mathrm{NClO}_{4}$ & & -0.76 & {$[17]$} \\
Pyridine & $\mathrm{LiCl}$ & & -0.80 & {$[17]$} \\
DMF & $\left(\mathrm{C}_{2} \mathrm{H}_{5}\right)_{4} \mathrm{NClO}_{4}$ & -0.88 & {$[15]$} \\
DMSO & $\left(\mathrm{C}_{2} \mathrm{H}_{5}\right)_{4} \mathrm{NCl}$ & & -0.86 & {$[16]$} \\
DMF & $\left.\left(\mathrm{C}_{2} \mathrm{H}_{5}\right)_{4} \mathrm{NClO}_{4} \mathrm{Pc}^{2-}\right] /\left[\mathrm{Mn}^{\mathrm{I}} \mathrm{Pc}^{2-}\right]$ & -1.18 & {$[15]$} \\
DMSO & $\mathrm{LiCl}$ & {$\left[\mathrm{Mn}^{\mathrm{I}} \mathrm{Pc}^{2-}\right] /\left[\mathrm{Mn}^{\mathrm{I}} \mathrm{Pc}^{3-}\right]$} & -1.41 & {$[17]$} \\
DMSO & $\left(\mathrm{C}_{2} \mathrm{H}_{5}\right)_{4} \mathrm{NClO}_{4}$ & {$\left[\mathrm{Mn}^{\mathrm{II}} \mathrm{Pc}^{3-}\right] /\left[\mathrm{Mn}^{\mathrm{II}} \mathrm{Pc}^{4-}\right]$} & -1.39 & {$[17]$} \\
\hline
\end{tabular}

DMF, dimethylformamide; DMSO, dimethylsulfoxide; DMA, dimethylacetamide. 

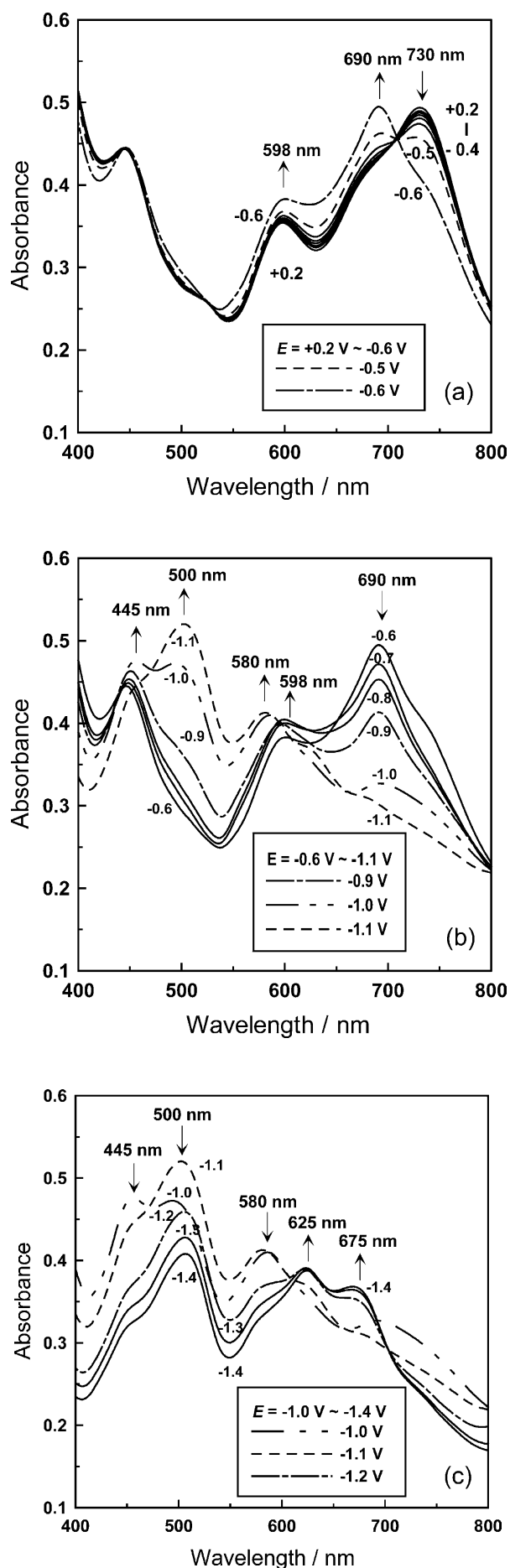

Fig. 3. (a) In-situ UV-vis absorption spectra of a fresh MnPc thin film switched in $1 \mathrm{M} \mathrm{KCl}$ at different reduced potentials: $E=+0.2$ to -0.6 $\mathrm{V}$ (vs. $\mathrm{Ag} \mid \mathrm{AgCl}$ ). (b) In-situ UV-vis absorption spectra of fresh $\mathrm{MnPc}$ thin film switched in $1 \mathrm{M} \mathrm{KCl}$ at different reduced potentials: $E=-0.6$ to $-1.1 \mathrm{~V}$ (vs. $\mathrm{Ag} \mid \mathrm{AgCl}$ ). (c) In-situ $\mathrm{UV}$-vis absorption spectra of fresh MnPc thin film switched in $1 \mathrm{M} \mathrm{KCl}$ at different reduced potentials: $E=-1.0$ to $-1.4 \mathrm{~V}$ (vs. $\mathrm{Ag} \mid \mathrm{AgCl}$ ).

3 (b), the applied potentials were from -0.6 to $-1.1 \mathrm{~V}$. Therefore, the $690 \mathrm{~nm}$ peak decayed and was replaced by a new major peak at $500 \mathrm{~nm}$ as the potentials became more negative than $-0.9 \mathrm{~V}$. The color of the MnPc thin film changed from greenish blue to purple. At the last stage, stage III, as represented in Fig. 3(c), where the potential range lies between -1.0 and $-1.4 \mathrm{~V}$, the absorbance peak at $500 \mathrm{~nm}$ decayed when a more negative potential was applied to the MnPc thin films. Two minor peaks appeared at 625 and $675 \mathrm{~nm}$.

The applied potentials at $-0.4,-1.0$, and $-1.2 \mathrm{~V}$ resulted in three obviously distinctive spectral changes that correspond to the three different reduction states of the $\mathrm{MnPc}$ thin films, respectively. There is consistency in the comparison between CVs results, as shown in Fig. 2 and the absorbance spectra in Fig. 3.

\subsection{Effect of cations}

Green and Faulkner [5] studied the electrochemistry of transition-MPcs and proved that solvent anions were inserted into the PC thin films as the compensated ions to maintain charge neutrality during the oxidation reaction. The sizes of anions do affect the insertion ability. The same results were also found by Kahl et al. [8] who stated that for the reversible oxidation and rereduction of $\mathrm{MgPc}$ thin film, smaller anions allow full oxidation at faster rates, whereas larger anions inhibit the oxidation.

As a consequence, cations should be inserted into the $\mathrm{MnPc}$ thin film during the reduction reactions to maintain charge neutrality. Cyclic voltammograms of the $\mathrm{MnPc}$ thin films in the solutions containing different kinds of cations are shown in Figs. 4-8. Different reduction peak potentials in the MnPc thin film purple state were observed due to the varied constitution of the cations. The order of the reduction potentials was $\mathrm{Li}^{+}$ $(-1.15 \mathrm{~V})<\mathrm{Na}^{+}(-1.13 \mathrm{~V})<\mathrm{K}^{+}(-1.05 \mathrm{~V})<\mathrm{Rb}^{+}$ $(-1.0 \mathrm{~V}) \approx \mathrm{Cs}^{+}(-1.0 \mathrm{~V})$, as seen in Figs. 4-8, respectively. The insertion ability of various cations was studied by comparing CVs under the same potential

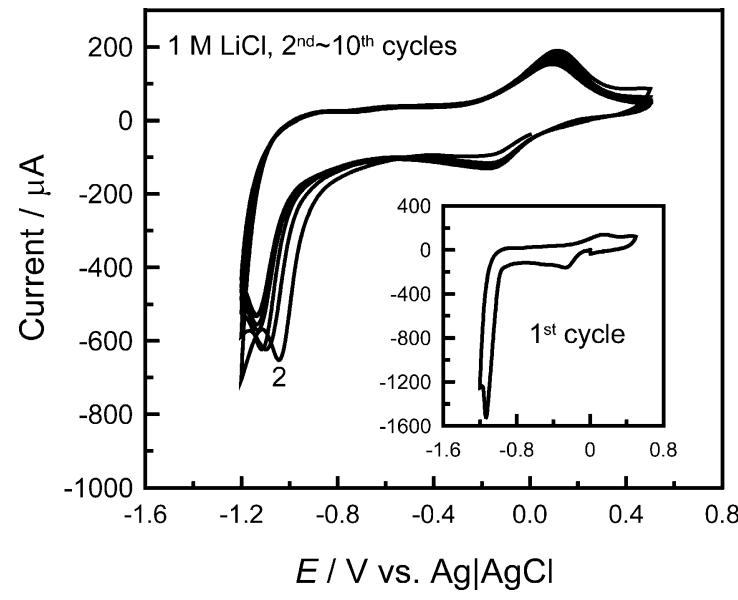

Fig. 4. Cyclic voltammograms of the MnPc thin film on a conductive FTO glass in $1 \mathrm{M} \mathrm{LiCl}$ for the first 10 cycles, scan rate $=20 \mathrm{mV} \mathrm{s}^{-1}$, electrode area $=2.4 \mathrm{~cm}^{2}$. 


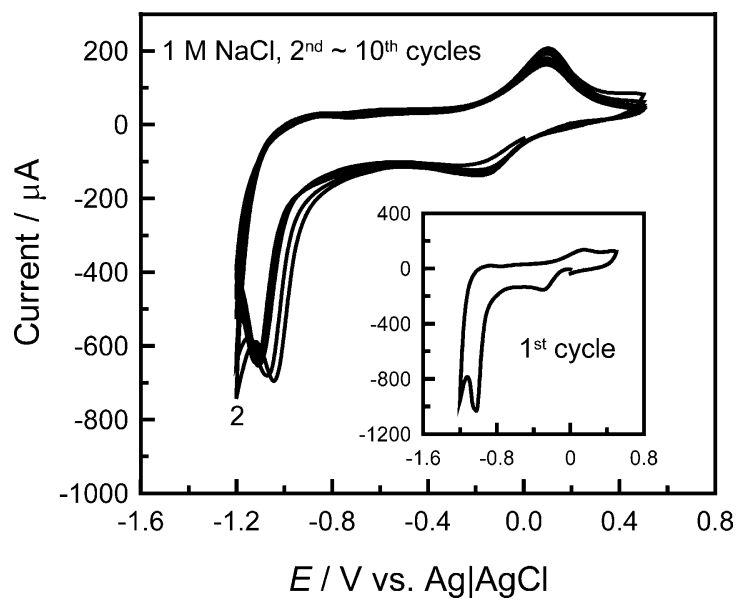

Fig. 5. Cyclic voltammograms of the MnPc thin film on a conductive FTO glass in $1 \mathrm{M} \mathrm{NaCl}$ for the first 10 cycles, scan rate $=20 \mathrm{mV} \mathrm{s}^{-1}$, electrode area $=2.4 \mathrm{~cm}^{2}$.

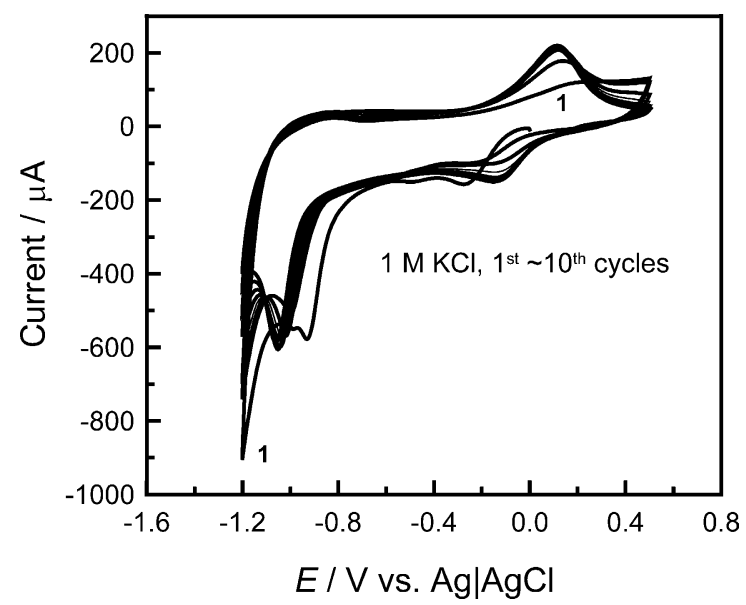

Fig. 6. Cyclic voltammograms of the MnPc thin film on a conductive FTO glass in $1 \mathrm{M} \mathrm{KCl}$ for the first 10 cycles, scan rate $=20 \mathrm{mV} \mathrm{s}^{-1}$, electrode area $=2.4 \mathrm{~cm}^{2}$.

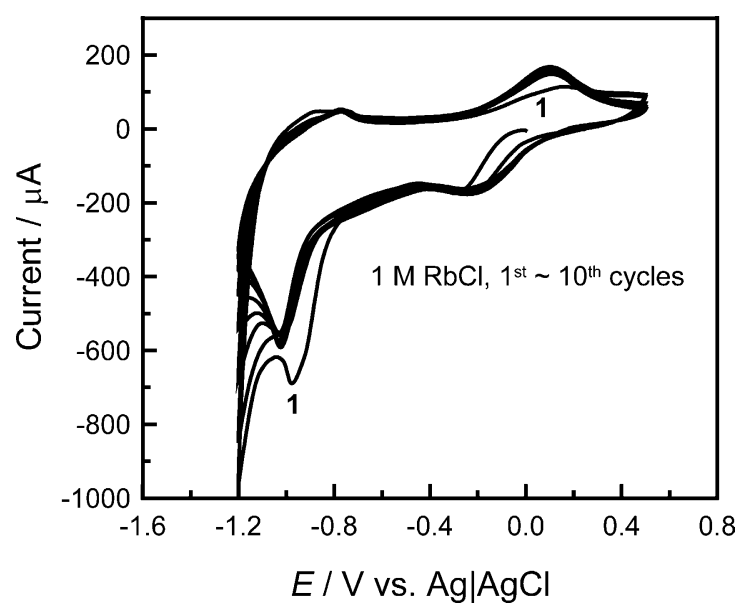

Fig. 7. Cyclic voltammograms of the MnPc thin film on a conductive FTO glass in $1 \mathrm{M} \mathrm{RbCl}$ for the first 10 cycles, scan rate $=20 \mathrm{mV} \mathrm{s}^{-1}$, electrode area $=2.4 \mathrm{~cm}^{2}$.

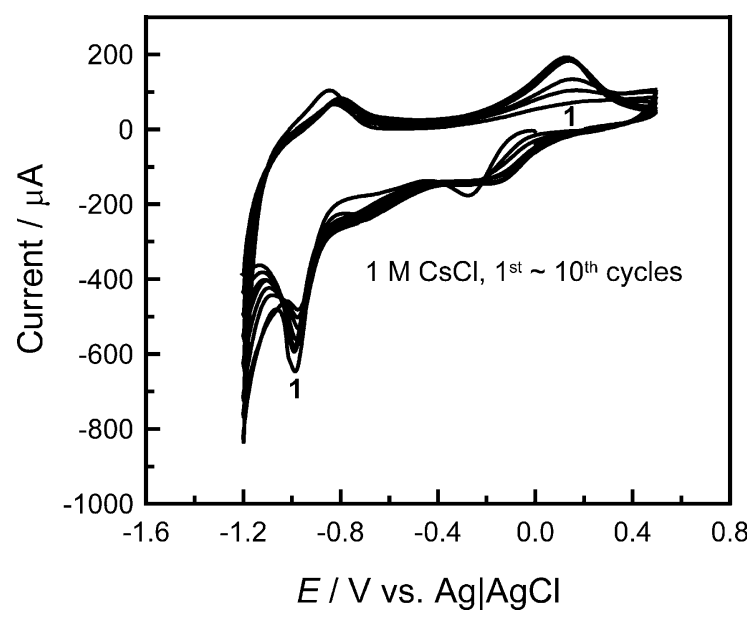

Fig. 8. Cyclic voltammograms of the MnPc thin film on a conductive FTO glass in $1 \mathrm{M} \mathrm{CsCl}$ for the first 10 cycles, scan rate $=20 \mathrm{mV} \mathrm{s}^{-1}$, electrode area $=2.4 \mathrm{~cm}^{2}$.

range and the same sweep rate. Since no attempt was made in this study to address the sweep dependence of $\mathrm{CVs}$ in electrolytes containing different cations, equilibrium conditions may not be achieved during the potential scan. Therefore, it should be stressed that the size effect of cations may be of kinetic origin, at least in part. In fact, the insertion ability decreases as the hydrated cation radii increase. This is expected from the kinetic point of view, as a more negative reduction potential was needed for larger hydrated cations. This suggests that the gap between the two PC molecular planes acts as a molecular sieve and sets a size limitation to the hydrated cations being inserted during reduction. The calculated radii from the limiting mobility using Stokes' law were $2.37,1.83,1.25,1.18$, and $1.19 \AA$ for $\mathrm{Li}^{+}, \mathrm{Na}^{+}, \mathrm{K}^{+}, \mathrm{Rb}^{+}$, and $\mathrm{Cs}^{+}$, respectively [7]. This agreed with the experiment results. The same result can be obtained by monitoring the current changes during the negative potential scan. In the solutions containing hydrated cations with smaller radii, such as $\mathrm{Rb}^{+}$or $\mathrm{Cs}^{+}$, the reduction current started to increase around $0.5 \mathrm{~V}$. However, in the case of $\mathrm{Li}^{+}$, which has a large hydrated radius, a reduction current was detected down to $-0.8 \mathrm{~V}$. The charge neutrality requirement suggests that cations inserted into the thin film in the MnPc reduction process will be ejected out of the thin film during the oxidative potential scan. Figs. 4-8 represent the ease of insertion and ejection corresponding to the size of the hydrated radii, where different peak shapes and current values exist for various cations at the oxidation peaks around $-0.8 \mathrm{~V}$. The largest peak current and the best defined peak shape was observed in the hydrated $\mathrm{Cs}^{+}$cation, followed by $\mathrm{Rb}^{+}, \mathrm{K}^{+}$, and $\mathrm{Na}^{+}$. In the case of the hydrated $\mathrm{Li}^{+}$cation, the oxidation peak barely exists.

The gap between the two PC molecular planes is about $3.4 \AA$ [1]. Cations with radii smaller than $1.7 \AA$ should be able to insert into the MnPc thin film easily 
during reduction. Thus, $\mathrm{K}^{+}, \mathrm{Rb}^{+}$, and $\mathrm{Cs}^{+}$cations can move into or out of the thin film freely. However, in the case of $\mathrm{Li}^{+}$and $\mathrm{Na}^{+}$, greater resistance will be encountered. A comparison of the charge consumed during the first and second cycles of the potential scans shows that the electrochemical reversibility was poor for solutions containing $\mathrm{Li}^{+}$and $\mathrm{Na}^{+}$, as can be seen by comparing the inset of Fig. 4 and the inset of Fig. 5 with Figs. 4 and 5. For example, during the negative potential scan, $\mathrm{Li}^{+}$cannot be inserted into MnPc thin films until a negative enough potential, or a sufficient driving force, is reached $(-1.0 \mathrm{~V})$. However, at this applied potential, the insertion of $\mathrm{Li}^{+}$may be through the interstices or some defects within the thin film. In the succeeding potential scans, a smaller resistance was encountered as a result of repeated cycling, leading to a less negative reduction potential at around $-1.0 \mathrm{~V}$. Besides, one should distinguish between electrochemical and chemical reversibility. Taking Figs. 4 and 5 as an example, even though the existence of the chemical reversibility is evident by the appearance of a peak around $-1.1 \mathrm{~V}$, the electrochemical reversibility is poor as judged by the CVs.

\subsection{Fabrication of the ECD}

To conduct a study on the possible use of MnPc in an $\mathrm{ECD}$, PAni thin film was chosen as a $\mathrm{CE}$ to fabricate a complementary ECD. This ECD, hereafter referred to as $\mathrm{MnPc} / \mathrm{KCl} / \mathrm{PAni}$, is shown in Fig. 9. In addition to the good reversibility and distinct color changes, the choice of PAni thin film as one of the electrodes was based on two considerations: (1) PAni is an oxidizing coloring material in conjunction with the reducing coloring $\mathrm{MnPc}$, which meets the requirement to fabricate a complementary ECD; (2) the darkening (oxidized state for PAni and reduced state for $\mathrm{MnPc}$ ) state is the same for these two thin films. The color states of PAni thin film in a $1 \mathrm{M} \mathrm{KCl}$ solution, as a function of the applied potential (vs. $\mathrm{Ag} \mid \mathrm{AgCl}$ ), can be described as follows: -0.5 (light yellow) $\rightarrow 0.5 \mathrm{~V}$ (green), while the polychromic characteristic of MnPc in the same electrolyte is: 0.5 (light green) $\rightarrow-0.5 \mathrm{~V}$ (green). Typical cyclic voltammograms for a vacuum deposited $\mathrm{MnPc}$ film and for an electrodeposited PAni film in $1 \mathrm{M} \mathrm{KCl}$ are shown in Fig. 10(a and b), respectively. The charge capacity of PAni $\left(2.3 \mathrm{mC} \mathrm{cm}^{-2}\right)$ was kept about the same as that of $\operatorname{MnPc}\left(2.1 \mathrm{mC} \mathrm{cm}^{-2}\right)$ before assembling the ECD. This is to ensure that the amount of charge released during oxidation from the PAni electrode $(-0.5-0.5 \mathrm{~V})$ is just enough to reduce the MnPc film $(0.5$ to $-0.5 \mathrm{~V})$, and vice versa. Before assembling, the PAni electrode was pre-polarized to the light yellow state at $-0.5 \mathrm{~V}$. The active dimension of the ECD was maintained at $0.5 \times$ $2.5 \mathrm{~cm}^{2}$, and $1 \mathrm{M} \mathrm{KCl}$ was employed as the electrolyte. Fig. 11 shows the half-cell potential distributions for an
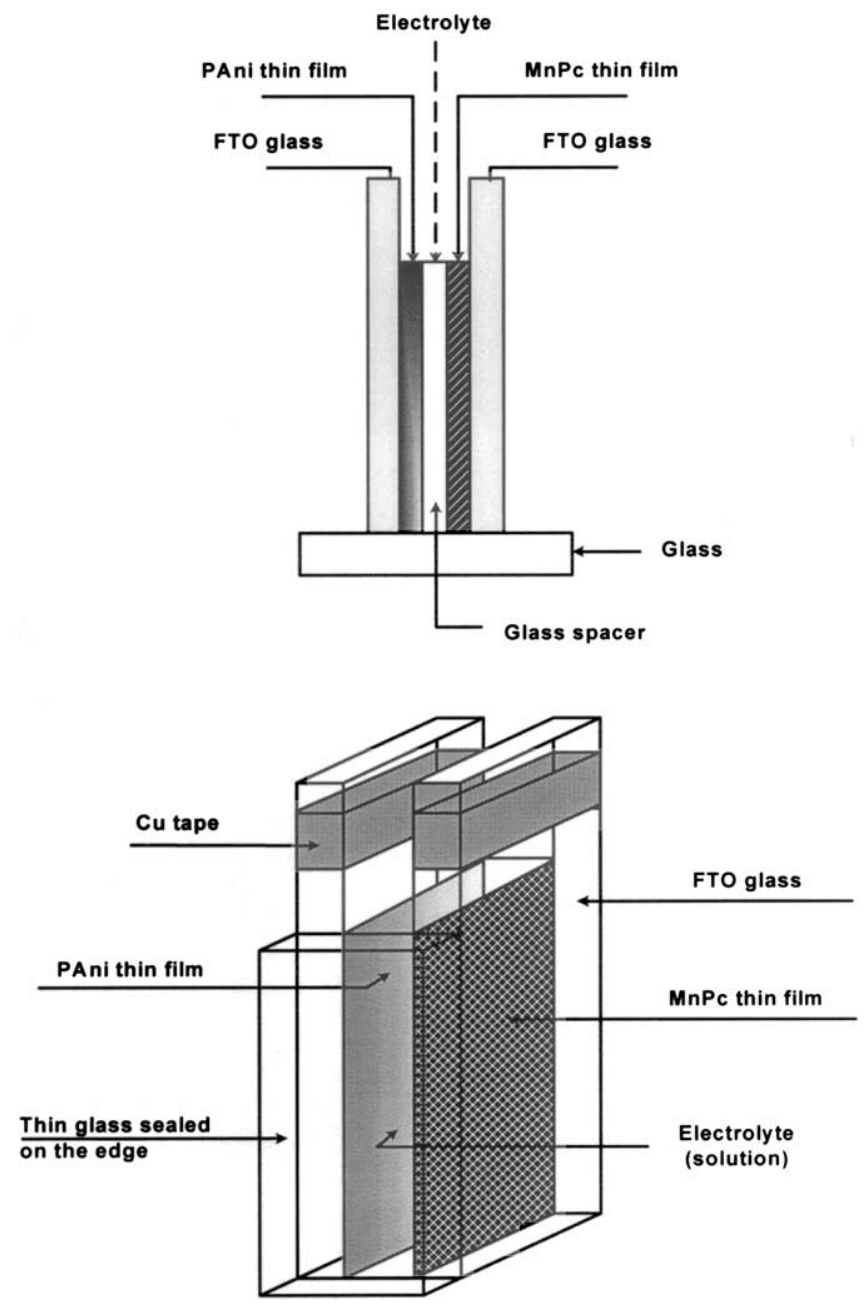

Fig. 9. The complementary ECD configuration of $\mathrm{MnPc} / \mathrm{KCl} / \mathrm{PAni}$.

ECD consisting of $\mathrm{MnPc}$ and PAni thin films. This plot gives the potential on each electrode as a function of the fractional charge passed or consumed per unit area $(q /$ $q_{\mathrm{T}}$ ) during the electrochromic switching, where $q$ is the charge consumed per unit area for a thin film electrode at a specific potential, and $q_{\mathrm{T}}$ is the total charge capacity of the same electrode in the operating potential region. For example, when the applied potential difference is $-1.0 \mathrm{~V}$ (MnPc vs. PAni), or $V_{\text {cell, darkening }}=-1.0 \mathrm{~V}$, the electrode potentials for both $\mathrm{MnPc}$ and PAni are at -0.5 and $0.5 \mathrm{~V}$, respectively. As long as the charge capacity ratio is kept at unity, the applications of cell potential at -1.0 and $+1.0 \mathrm{~V}$ will ensure the ECD being operated in green and light green, respectively.

The transmittance (at $550 \mathrm{~nm}$ ) at the geometric center and the current during cyclic potentiostatic switching are presented in Fig. 12(a and b), respectively, for the first two cycles. The sample was darkened or bleached by the application of -1.0 or $+1.0 \mathrm{~V}$ for $30 \mathrm{~s}$, respectively. The voltage is the potential between the $\mathrm{MnPc}$ and the PAni thin films (MnPc vs. PAni). The ECD was switched reversibly between green $(-1.0 \mathrm{~V})$ 

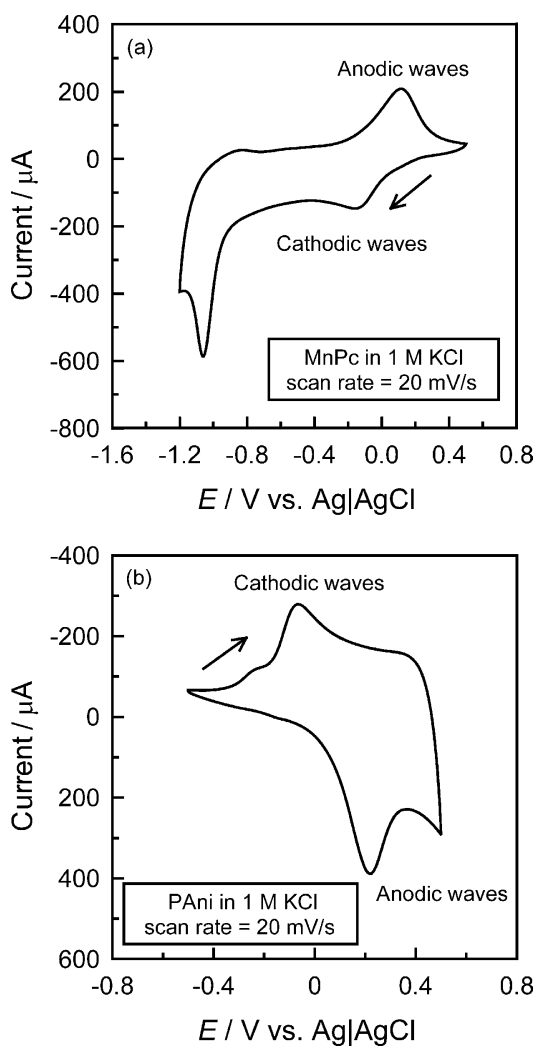

Fig. 10. (a) Typical cyclic voltammogram for a vacuum deposited MnPc film in $1 \mathrm{M} \mathrm{KCl}$. (b) Typical cyclic voltammogram for an electrodeposited PAni film in $1 \mathrm{M} \mathrm{KCl}$. The preparation conditions,

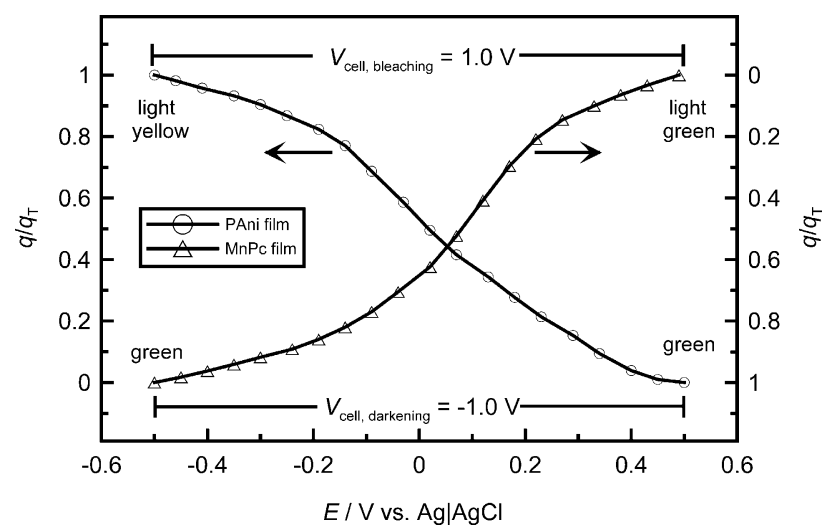

Fig. 11. Half-cell potential distributions for an ECD consisting of MnPc and PAni thin films. This plot is obtained from Fig. 10. $q$ is the charge capacity consumed for a thin film electrode at a specific potential, and $q_{\mathrm{T}}$ is the total charge capacity of the same electrode in the operating potential region. $q_{\mathrm{T}} \approx 2.2 \mathrm{mC} \mathrm{cm}^{-2}$ for both $\mathrm{MnPc}$ and PAni thin films. The charge capacity ratio is maintained at unity.

and light green $(+1.0 \mathrm{~V})$. The transmittance of the device varied from 60 to $17 \%$ at $550 \mathrm{~nm}$. It can also be seen that the charges consumed, for both the darkening and bleaching processes, were very close, which is an indication of good reversibility for the ECD.
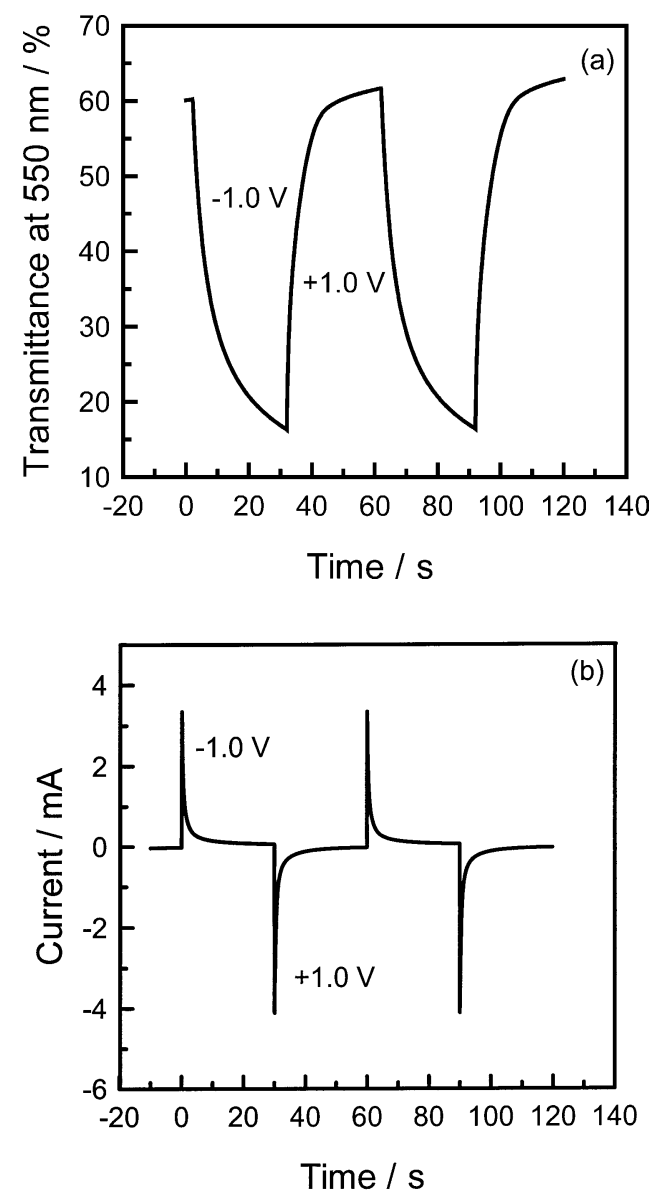

Fig. 12. (a) Transmittance response of the ECD (PAni/KCl $(1 \mathrm{M}) /$ $\mathrm{MnPc})$ at $550 \mathrm{~nm}$ switched by a double potential step. Switching potentials: $-1.0 \mathrm{~V}$ for darkening, $+1.0 \mathrm{~V}$ for bleaching; and (b) the corresponding current transient.

One of the important factors that determine the stability of an ECD is the choice of operating potential [18]. Increasing the operating potential window can widen the transmittance window. However, if the operating voltage is outside the safe range, some irreversible side reactions will occur, leading to a large difference between the coloring and bleaching charge consumption and, finally causing the electrochromic thin film to crash. If MnPc thin film is reduced to the purple state, which itself is an irreversible reaction, the charge consumed during the reduction (coloring) will be greater than that for oxidation, as is seen in Fig. 2. The excess charges might oxidize PAni into the blue state or even the purple state, which is also irreversible. Another factor that affects the performance of an ECD is the composition of the electrolyte. The PAni purple state is stable under an acidic environment. In other words, it would be hard for PAni to reduce back to the green state if there are no protons in the electrolyte. For MnPc, however, the reversibility is greatly decreased in the presence of protons (not shown here). Thus, the lifetime of the ECD will be shortened if it is operated in the 
purple state, regardless of the existence of protons. Organic electrolytes or solid-state electrolytes should be used to improve the performance of the ECD. Experiments are under way to verify this concept.

\section{Conclusions}

In the potential range between 0.50 and $-1.10 \mathrm{~V}$ (vs. $\mathrm{Ag} \mid \mathrm{AgCl}), \mathrm{MnPc}$ thin film undergoes two reversible color changes in aqueous solutions containing Group IA cations. In a more negative potential range, says, more negative than $-1.20 \mathrm{~V}$, three different stages of $\mathrm{MnPc}$ thin film are involved. In order to maintain the electrolyte neutrality, the insertion of cations in the electrolyte is necessary to reduce MnPc thin film. The size of Group IA cations affects the voltammetric behavior of MnPc film at the negative reaction potentials. The insertion ability decreases as the hydrated cation radii increase. This is expected, as a more negative reduction potential was needed for larger hydrated cations. All of these were demonstrated by observing the voltammetric difference for $\mathrm{MnPc}$ thin films in the solutions containing Group IA hydrated cations.

A complementary $\mathrm{MnPc}-\mathrm{PAni} \mathrm{ECD}$, in combination with $1 \mathrm{M} \mathrm{KCl}$, was fabricated. Reversible color changes in the ECD, switched between light green and green, were observed. The transmittance window at $550 \mathrm{~nm}$ lies between 60 and $17 \%$ with an operating potential of 1.0 and $-1.0 \mathrm{~V}$, respectively. The charges consumed during the coloring (reducing) and the bleaching (oxidizing) reactions in the ECD were almost equal. If the $\mathrm{MnPc}$ or PAni thin film purple state is involved in the coloring reactions, the stability and reversibility of the ECD will be greatly reduced because irreversible reactions are very likely to occur on both the MnPc and PAni thin films.

\section{Acknowledgements}

Helpful discussions with Dr. Lin-Chi Chen are appreciated. We would also like to thank Dr. YuhHan Shing, former Senior Vice President of Sinonar Corporation, Hsinchu, Taiwan, for providing the conductive F-doped $\mathrm{SnO}_{2}$-coated glass substrates. This work was supported by the National Research Council of R.O.C. under grant no. NSC 89-2214-E002-017.

\section{References}

[1] F.H. Moser, A.L. Thomas, Phthalocyanine Compounds, Reinhold Publishing Corp, New York, 1963, p. 2.

[2] G.C.S. Collins, D.J. Schiffrin, J. Electroanal. Chem. 139 (1982) 335.

[3] P.N. Moskalev, I.S. Kirin, Russ. J. Phys. Chem. 46 (1972) 1019.

[4] J.L. Kahl, L.R. Faulkner, Paper Presented at the 11th Central Regional Meeting of the American Chemical Society, Columbus, OH, May 7-9, 1979.

[5] J.M. Green, L.R. Faulkner, J. Am. Chem. Soc. 105 (1983) 2950.

[6] C.M. Lampert, Solar Energy Mater. 11 (1984) 1.

[7] K. Itaya, T. Ataka, S. Toshima, J. Am. Chem. Soc. 104 (1982) 4767.

[8] J.L. Kahl, L.R. Faulkner, K. Dwarakanath, H. Tachibawa, J. Am. Chem. Soc. 108 (1986) 5434.

[9] N. Toshima, S.I. Kawamura, T. Tominaga, Chem. Lett. (1993) 1299.

[10] M.M. Nicholson, F.A. Pizzarello, J. Electrochem. Soc. 126 (1979) 1490.

[11] M.M. Nicholson, F.A. Pizzarello, J. Electrochem. Soc. 127 (1980) 821.

[12] M.M. Nicholson, F.A. Pizzarello, J. Electrochem. Soc. 128 (1981) 1740.

[13] G.C. Collins, D.J. Schiffrin, US Patent 4,427,267, 1984.

[14] N. Toshima, T. Tominaga, S.I. Kawamura, Bull. Chem. Soc. Jpn. 69 (1996) 245.

[15] A.B.P. Lever, S.R. Pickens, P.C. Minor, S. Licoccia, B.S. Ramaswamy, K. Magnell, J. Am. Chem. Soc. 103 (1981) 6803.

[16] A.B.P. Lever, J.P. Wilshire, Can. J. Chem. 54 (1976) 2514.

[17] A.B.P. Lever, P.C. Minor, J.P. Wilshire, Inorg. Chem. 20 (1981) 2550.

[18] K.C. Ho, L.C. Chen, C.C. Lee, Proc. of SPIE 3788, 1999, p. 120. 